\title{
Effect of the Extrusion Ratio on the Mechanical Properties of As-Forged Mg-8Al-0.5Zn Alloy
}

\author{
Youngseon Lee', Sang-ik Lee', and Jonghun Yoon ${ }^{2, \#}$ \\ 1 Process Commercialization Center, Korea Institute of Material Science, 797, Changwon-daero, Seongsan-gu, Changwon-si, Gyeongsangnam-do, 642-831, South Korea \\ 2 Department of Mechanical Engineering. Hanyang University, 55, Hanyangdaehak-ro, Sangnok-gu, Ansan-si, Gyeonggi-do, 426-791, South Korea \\ \# Corresponding Author / E-mail: yooncsmd@gmail.com, TEL: +82-31-400-5255, FAX: +82-31-436-8146
}

KEYWORDS: Magnesium alloy, Mg-8Al-0.5Zn, Warm forging, Extrusion ratio, Precipitate

This paper demonstrates the effect of the extrusion ratio on the mechanical properties of the as-forged Mg-8Al-0.5Zn alloy. Three extruded Mg bars with the extrusion ratio of 9:1, 16:1, and 25:1 are prepared in the same extrusion condition, which are applied to the warm forging test to obtain the different microstructure with respect to the degree of extrusion effect in $\mathrm{Mg}$ alloys. The extrusion ratio over 16:1 has little effect on the mechanical properties of the as-extruded bars since the average grain size and amount of precipitates hardly change. The forgeability of the highly extruded bar is improved around flange area while the mechanical properties are slightly enhanced. The rod-type and particle-type precipitates tend to be favored in the as-forged microstructure with the extrusion ratio over 16:1.

\section{Introduction}

Magnesium (Mg) alloys have been of great interest in transportation and electronics industries to make a light-weight design although they show limited formability and strong tension-compression symmetry in plastic flow at the ambient temperature. ${ }^{1-6}$ Most of applications with magnesium alloys have been produced by the die casting process since it guarantees high productivity and sufficient strength. However, casting defects and porosities in the die casting process do not only reduce ductility but also degrade mechanical properties of the final product, inevitably. ${ }^{7}$ To overcome these drawbacks, warm forging process with wrought $\mathrm{Mg}$ alloys such as extruded bars has been applied extensively to a bulk forming for steering knuckles, control arms, and high-strength road wheels, ${ }^{8}$ which considerably improves strength and ductility of the final forged product. Skubisz et al. ${ }^{9}$ demonstrated the closed-die forging to test forgeability with $\mathrm{Mg}-\mathrm{Al}-\mathrm{Zn}$ magnesium alloys in a complex state of stress and strain. Shan et al. ${ }^{10}$ proposed a complex shape forging technology by adopting fully enclosed die forging and a combined female die. Wang et al. ${ }^{11}$ have intended to induce dynamic recrystallization (DRX) to the initial billet by imposing a pre-strain, which enables AZ80 alloy wheels and AZ31 alloy brackets being forged successfully for near-net-shape forming.

During warm forging process with extruded $\mathrm{Mg}$ bars, mechanical properties of the final product are substantially influenced by the quality of as-cast ingot such as the grain size and uniformity of the grain structure depending on the extrusion conditions. However, it is not possible to increase the extrusion ratio tremendously because it does not only require huge facilities for extrusion process but also increases the production cost exponentially. Furthermore, it is not necessary to increase the extrusion ratio excessively in mass production since insufficient extrusion ratio in the extruded bar is able to be compensated by the subsequent plastic forming with dynamic recrystallization (DRX) during the warm forging process. Therefore, it is quite interesting to correlate the extrusion ratio with the mechanical properties of the forged product, which is able to suggest appropriate extrusion ratio in the warm forging process with $\mathrm{Mg}$ alloys.

Many researches concerning the effect of the extrusion ratio have been focused on the microstructure and variation of mechanical properties of the extruded bars with respect to various extrusion ratios. Tong et al. ${ }^{12}$ showed that the volume fraction of DRXed grains remarkably increases with the increase of the extrusion ratio, but the average DRXed grains size is almost unchanged. It is also noted that the extrusion ratio had only little effect on the tensile properties of the as-extruded bars due to the similar strengthening effect from the unDRXed and DRXed grains. Wen et al. ${ }^{13}$ conducted various hot extrusions with the ratios of $11: 1,25: 1$ and 44.4:1 in which they showed that the increase of the extrusion ratio enhances the ductility and tensile strength of Mg-Nd-Zn-Zr magnesium alloy. Chen et al. ${ }^{14}$ demonstrated that the ultimate tensile strength (UTS) and yield strength 
(YS) of AZ31 alloy increase obviously with extrusion ratio increasing to 24, then the UTS and YS are little influenced by further increasing extrusion ratio. Uematsu et al. ${ }^{15}$ have investigated grain refinement and fatigue behavior with respect to the extrusion ratio. Chang et al. ${ }^{16}$ examined the effect of the grain size and texture effect on compression behavior of hot-extruded $\mathrm{Mg}-3 \mathrm{Al}-1 \mathrm{Zn}$ alloys at room temperature.

However, it has not been studied for the effect of the extrusion ratio on the microstructure and mechanical properties of the forged $\mathrm{Mg}$ product, directly. In this paper, the extruded Mg-8Al-0.5Zn bars with the ratio of $9: 1,16: 1$, and $25: 1$ were manufactured in the same extrusion conditions, which were provided into the warm forging process. Depending on the various extrusion ratios, the microstructure and mechanical properties of the forged $\mathrm{Mg}-8 \mathrm{Al}-0.5 \mathrm{Zn}$ product are investigated in terms of grain structure with the optical microscopy and the yield, ultimate tensile strengths in the uniaxial tensile tests, which can suggest optimum extrusion ratio in the $\mathrm{Mg}$ warm forging process.

\section{Experimental Procedures}

\subsection{Extrusion Process}

To obtain three different extrusion ratios of 9:1, 16:1, and 25:1, ascast Mg-8Al-0.5Zn ingots (Table 1) with the diameter of $155 \mathrm{~mm}$ and length of $300 \mathrm{~mm}$ are prepared. Table 2 indicates the extrusion conditions in which the container and as-cast ingot temperature remain $573 \mathrm{~K}$ and ram speeds are controlled adaptively such as $1.7,0.9$, and $0.6 \mathrm{~mm} / \mathrm{sec}$ depending on the extrusion ratio to fix the outlet velocity of the material flow which influences the extrusion temperature considerably. Fig. 1 shows the extrusion facility and three kinds of extruded bars depending on the extrusion ratios. The final diameters of the extruded $\mathrm{Mg}-8 \mathrm{Al}-0.5 \mathrm{Zn}$ bars are 54,40 , and $32 \mathrm{~mm}$ with respect to the extrusion ratios of 9:1, 16:1, and 25:1, which are applied to the warm forging process at the temperature of $523 \mathrm{~K}$ as introduced in the Section 2.2 after mechanical machining into the same diameter.

Microstructures of the extruded specimens have investigated along the extrusion direction with the optical microscopy. The microstructures of the extruded bars according to various extrusion ratios were investigated with optical micro-scope (OM) using an NIKON EPIPHOT200 in which there is no substantial difference in the average grain size as shown in Figs. 2(b) and 2(d) while the as-cast bar shows huge grains and $\mathrm{Mg}_{17} \mathrm{Al}_{12}$ precipitates ${ }^{17}$ near grain boundaries as depicted in Fig. 2(a).

Fig. 2 demonstrates comparison of the microstructures between the ascast and as-extruded with respect to various extrusion ratios in which the average grain size is over $40 \mu \mathrm{m}$ in the as-cast. Due to the DRX, it reduces to the average grain size of $10 \sim 12 \mu \mathrm{m}$ with the extrusion ratio of $9: 1$ as shown in Fig. 2(b). However, there is no dramatic reduction in the grain size with increase of the extrusion ratio up to $25: 1$, then it is recrystallized to $5 \sim 8 \mu \mathrm{m}$ since the rate of recrystallization becomes saturated in the extrusion ratio around 25:1 as depicted in Figs. 2(c) and 2(d).

In order to evaluate the mechanical properties of the extruded bars with respect to the various extrusion ratios, tensile tests are conducted with the strain rate of $0.001 / \mathrm{sec}$ at room temperature as shown in Fig. 3. Three tensile specimens are fabricated from the extruded bars with the extrusion ratio of 9:1,16:1, and 25:1 along the extrusion direction with the standard in ASTM B557M. The YS and UTS of the extruded bars are enhanced gradually as the extrusion ratio increases while they dramatically increase compared with those of the as-cast ingot. The YS and UTS of the extruded bars are little influenced by further increasing

Table 1 Chemical composition of Mg-8Al-0.5Zn ingot

\begin{tabular}{cccccc}
\hline \multirow{2}{*}{ Mg alloy } & \multicolumn{5}{c}{ Chemical composition (\%) } \\
\cline { 2 - 6 } & $\mathrm{Al}$ & $\mathrm{Zn}$ & $\mathrm{Mn}$ & $\mathrm{Si}$ & etc. \\
\hline AZ80 & 8.6 & 0.58 & 0.30 & 0.013 & Bal. \\
\hline
\end{tabular}

Table 2 Extrusion conditions

\begin{tabular}{ccccc}
\hline $\begin{array}{c}\text { Extrusion } \\
\text { ratio }\end{array}$ & $\begin{array}{c}\text { Ram speed } \\
(\mathrm{mm} / \mathrm{sec})\end{array}$ & & $\begin{array}{c}\text { Extrusion } \\
\text { rate }(\mathrm{mm} / \mathrm{sec})\end{array}$ & $\begin{array}{c}\text { Final } \\
\text { Diameter }(\mathrm{mm})\end{array}$ \\
\hline 9 & $1.7 \pm 0.5$ & & \multirow{2}{*}{15} & 54 \\
\cline { 1 - 2 } \cline { 5 - 5 } & & & & 40 \\
\hline $16: 1$ & $0.9 \pm 0.5$ & & 32 \\
\hline $25: 1$ & $0.6 \pm 0.5$ & & &
\end{tabular}

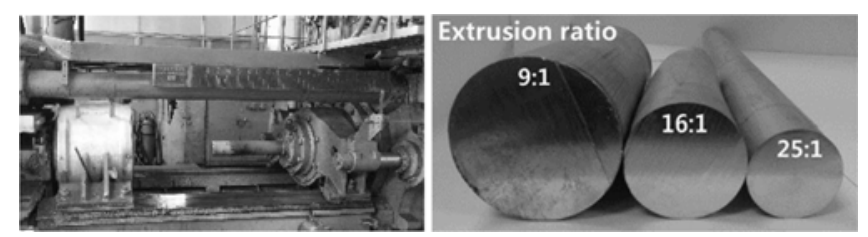

Fig. 1 Extrusion facility and as-extruded bar

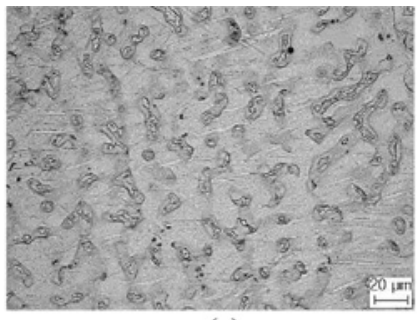

(a)

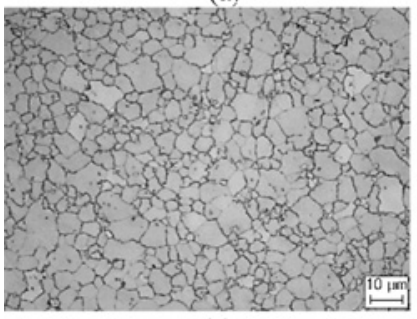

(c)

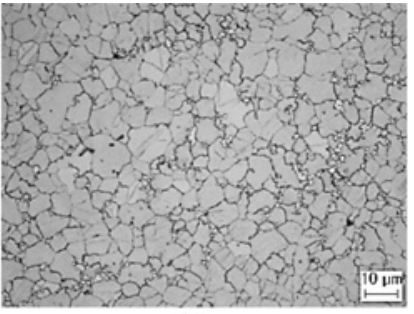

(b)

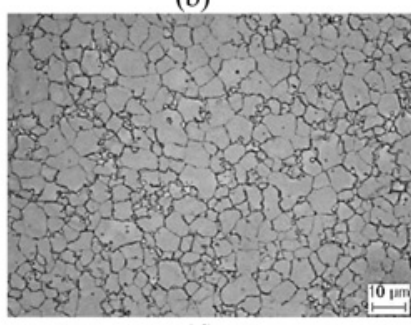

(d)
Fig. 2 Comparison of initial microstructures; (a) As-Cast ingot (b) AsExtruded (9:1) (c) As-Extruded (16:1) (d) As-Extruded (25:1)

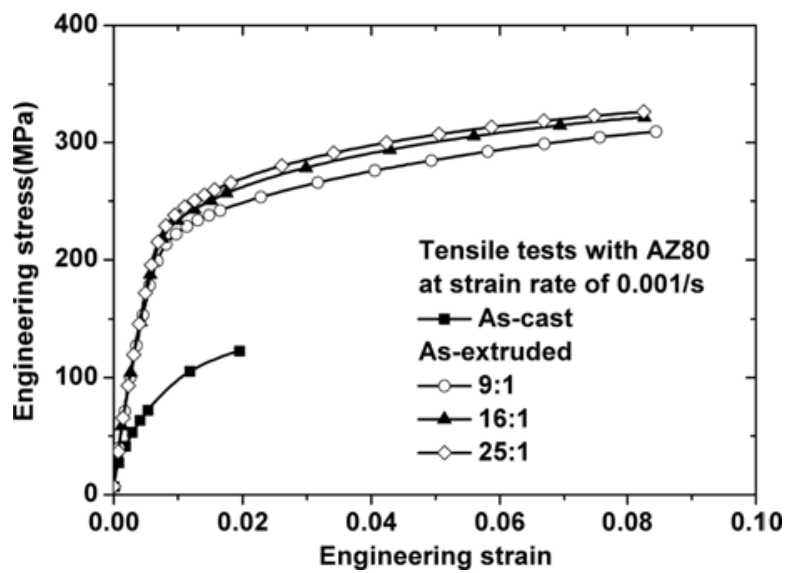

Fig. 3 Comparison of tensile test results with respect to extrusion ratio at room temperature 
extrusion ratio over 16 as shown in Fig. 3. It is because the variation of the average grain sizes and amount of precipitates are comparably small with respect to the extrusion ratio of 9:1,16:1, and 25:1 in the extrusion process as shown in Figs. 2(b) and 2(d).

\subsection{Warm Forging of Extruded Bar}

During warm forging process, ${ }^{18}$ the extruded $\mathrm{Mg}$ bars tends to undergo the DRX which considerably affects the mechanical properties of the final product since it reduces the grain size, dislocation density, and the accumulated energy to facilitate plastic deformation. ${ }^{2,19,20}$ In order to investigate the effect of extrusion ratio on the subsequent plastic deformation, warm forging process is carried out with the three extruded Mg bars with three extrusion ratios of 9:1, 16:1, and 25:1.

It is required to design the punch and die-set for the warm forging test with $\mathrm{Mg}$ alloys in a small scale since it consumes huge amount of billet and time to conduct experiment. Fig. 4 demonstrated the layout of the punch and die-set for the type of tensile specimen forging, which is able to induce complex plastic deformation into the extruded Mg bars as well as preserve the shape of the tensile specimen after warm forging since it is machined into the tensile test specimen for evaluating mechanical properties of the forged one as shown in Fig. 5. The warm forging tests are conducted in a 200-ton hydraulic press and the working temperature is set to $523 \mathrm{~K}$ by the heating chamber as depicted in Fig. 4(a). Table 3 indicates the warm forging conditions with the extruded $\mathrm{Mg}$ bars. It takes 1.5 minutes to elevate the temperature of the initial specimen to $523 \mathrm{~K}$ right after it is placed on the pre-heated die-set. Then, it is pressed when the current temperature from the attached thermocouples on the die-set guarantees the target temperature of 523K.

Fig. 6 shows the comparison results of the test specimens forged at $523 \mathrm{~K}$ with extruded bars according to the extrusion ratio of 9:1, 16:1, 25:1 and as-cast ingot. While severe cracks around the flange area are investigated distinctly in the forged specimen with as-cast ingot, flange and sharp corner are precisely forged when applying the extruded bars with higher extrusion ratio as shown in Figs. 6(c) and 6(d). It is noted

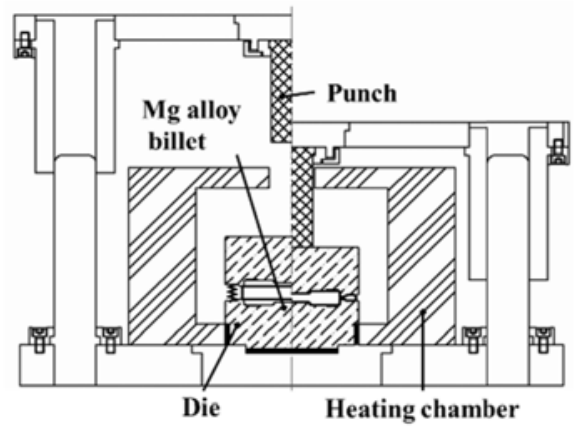

(a)

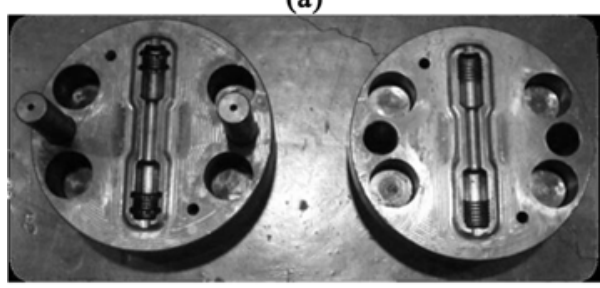

(b)

Fig. 4 Layout of punch and die for complex shape forging at the elevated temperature; (a) Heating chamber (b) Punch and die that a sound forged part in terms of good forgeability and net-shape can be produced with the extruded bars with extrusion ratio over 16:1.

\section{Results and Discussions}

In order to evaluate the mechanical properties of the as-forged Mg$8 \mathrm{Al}-0.5 \mathrm{Zn}$ alloys according to the extrusion ratios, Vickers hardness and tensile tests are conducted in test specimens which are obtained from the warm forging test in Section 2.2. Fig. 7 shows the variation of Vickers hardness with respect to extrusion ratio for as-extruded and as-forged

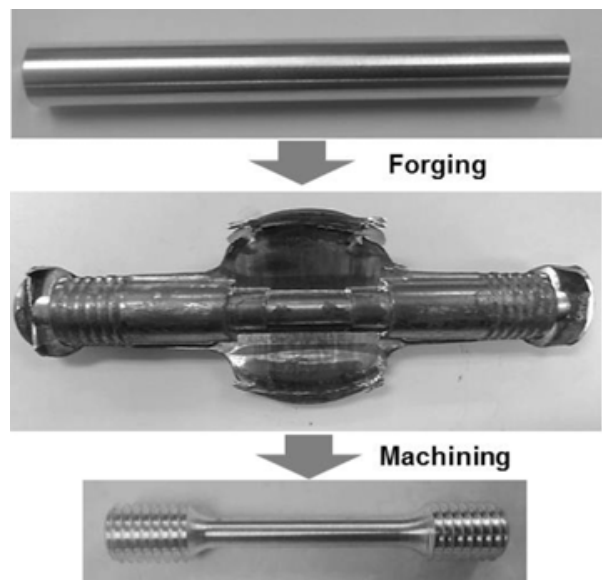

Fig. 5 Test procedure for evaluating mechanical properties from complex shape forging

Table 3 Warm forging conditions

\begin{tabular}{cc}
\hline \multirow{2}{*}{ Materials } & Mg-8Al-0.5Zn \\
\cline { 2 - 2 } & As-Cast, As-Extruded $(9: 1,16: 1,25: 1)$ \\
\hline Specimen size $(\mathrm{mm})$ & $\varnothing 15.0 \times 124.0 \mathrm{~mm}$ (cylinder type) \\
\hline Temperature $(\mathrm{K})$ & 523 \\
\hline Head speed $(\mathrm{mm} / \mathrm{sec})$ & 30 \\
\hline Facility & 200ton hydraulic press \\
\hline Lubrication & Graphite
\end{tabular}

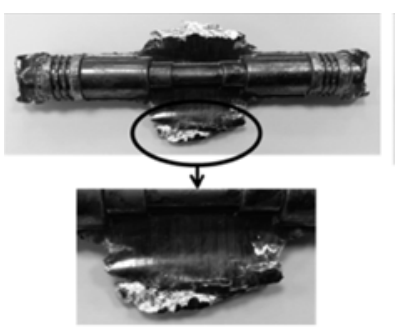

(a)

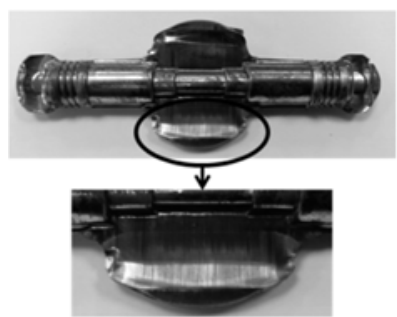

(c)

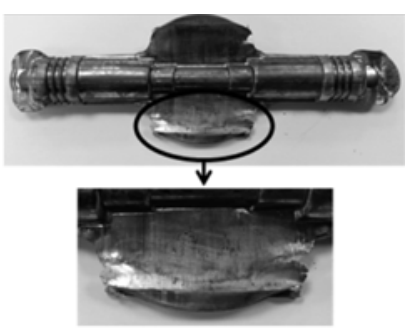

(b)

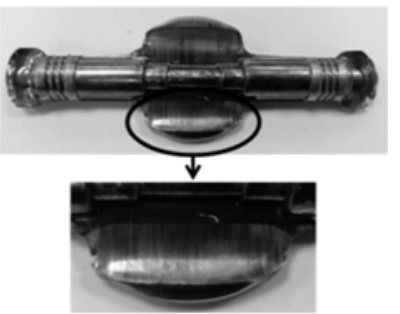

(d)
Fig. 6 Comparison of test specimen forged at 523K; (a) As-Cast (b) As-Extruded (9:1) (c) As-Extruded (16:1) (d) As-Extruded (25:1) 
where they show the saturated hardness for the extrusion ratio over 9:1.

Fig. 8 shows the comparison results of tensile test for the as-extruded and as-forged in which the increases of the YS are 80,85 , and $83 \mathrm{MPa}$ and, for the UTS, 57, 48, and $46 \mathrm{MPa}$ with respect to extrusion ratio of 9:1, $16: 1,25: 1$, respectively. While the fracture elongations are not critically influenced by the extrusion ratio over $9: 1$, they decrease from $8.5 \%$ to $6 \%$ from the warm forging effect. During the warm forging process, it does not only experience the DRX but also has large amount of precipitates, which accelerate the inhomogeneity in terms of grain size distribution and various phases such as $\alpha, \beta$, and $\alpha+\beta$. That is why the elongation-to-failure tends to be degraded in the as-forged specimens. Especially, a big difference in grain size between as-received and recrystallized tends to decrease the elongation-to-failure even though the average grain size reduces from the DRX at the elevated forming temperature.

$\mathrm{OM}$ investigation in the as-forged has been performed on the axial direction of the specimen as shown in Fig. 6. As shown in Fig. 9, it demonstrates microstructure in the as-forged at the elevated temperature, it slightly reduces to the grain size between $5 \mu \mathrm{m}$ and $8 \mu \mathrm{m}$ in the extrusion ratio of 9:1 while decreasing $4 \mu \mathrm{m}$ with the extrusion ratio over 16:1 including 25:1 (Figs. 9(c) and 9(d)).

Fig. 9 shows the microstructures forged at $523 \mathrm{~K}$ in $\mathrm{OM}$ investigation with respect to extrusion ratio in which the larger fraction of recrystallized fine grains and precipitates are observed as the higher

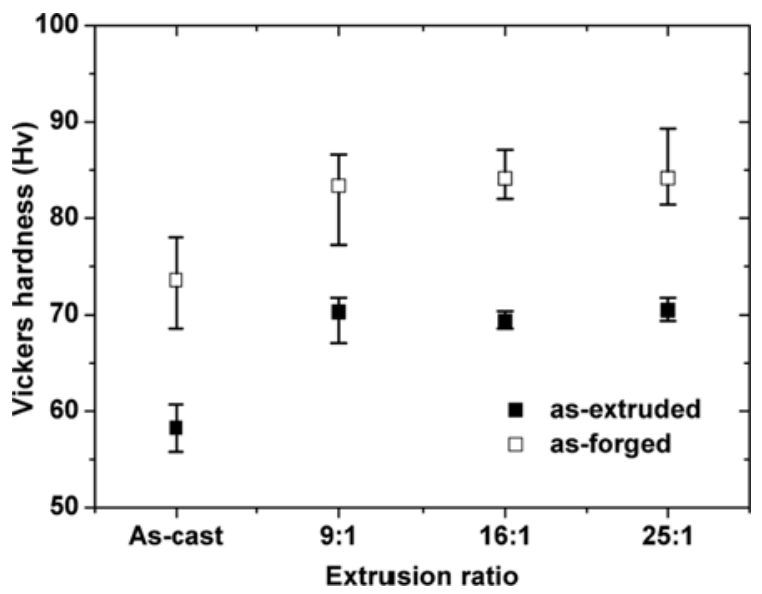

Fig. 7 Variation of Vickers hardness with respect to extrusion ratio for as-extruded and as-forged at $523 \mathrm{~K}$

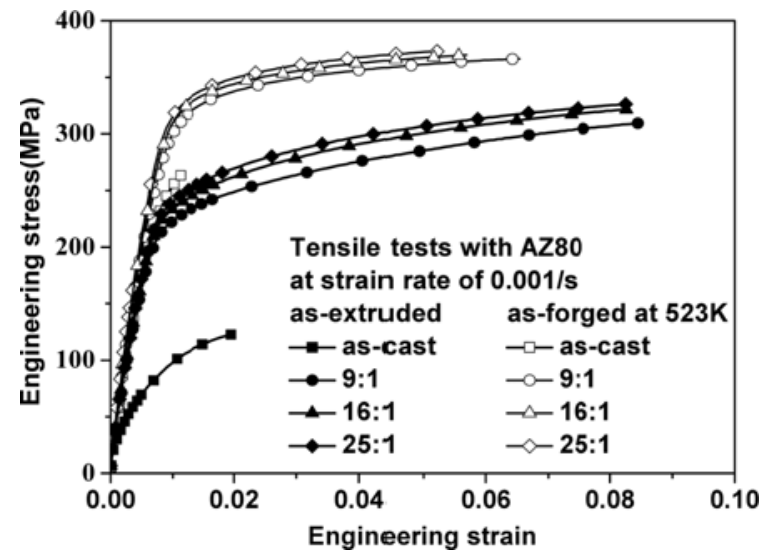

Fig. 8 Comparison of tensile test results for as-extruded and as-forged with respect to extrusion ratio extrusion ratio is applied. Wang et al. ${ }^{21}$ and Braszczyńska-Malik ${ }^{17}$ have examined the evolution of precipitates of Al-Mg alloys for the $\mathrm{T} 5$ heat

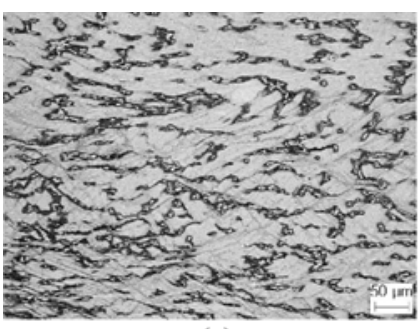

(a)

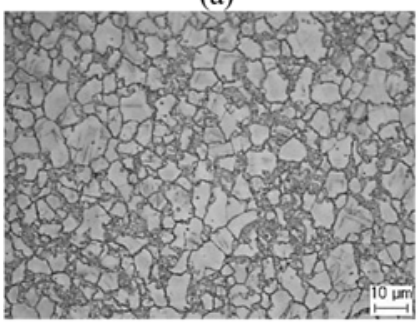

(c)

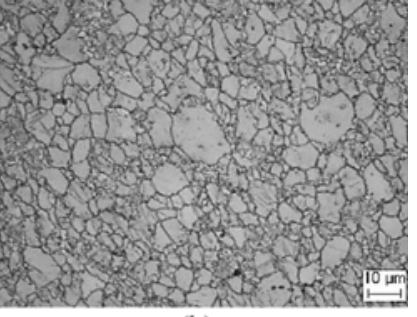

(b)

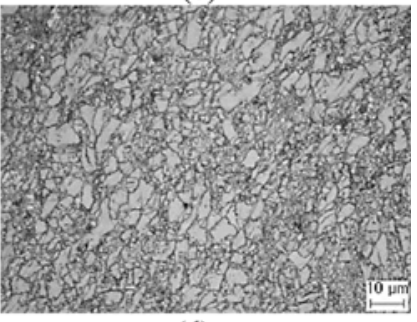

(d)
Fig. 9 Comparison of microstructures forged at 523K in $\mathrm{OM}$ investigation with respect to extrusion ratio; (a) As-Cast (b) 9:1 (c) $16: 1$ (d) $25: 1$
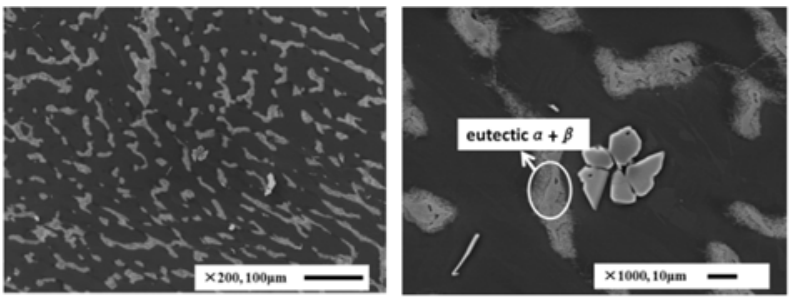

(a)
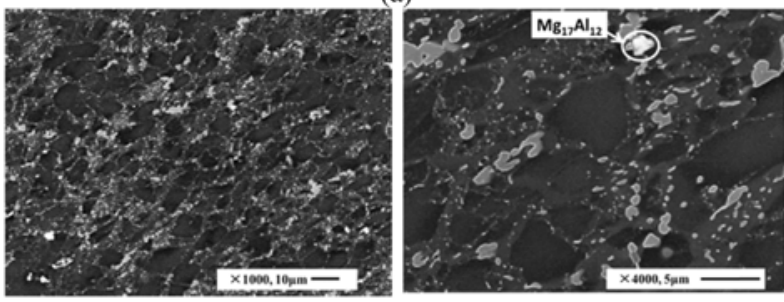

(b)
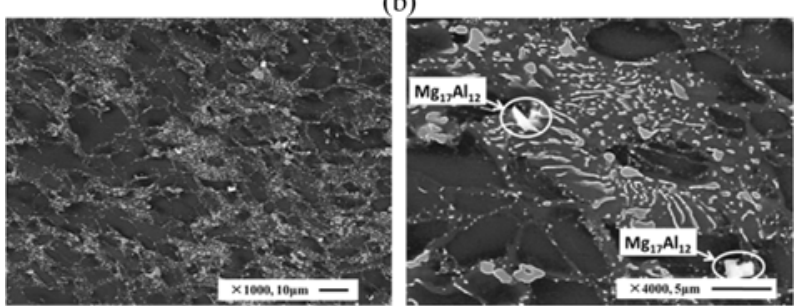

(c)
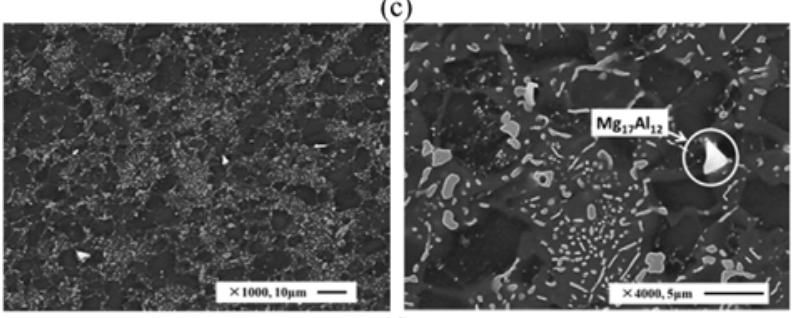

(d)

Fig. 10 Comparison of microstructures forged at 523K in SEM investigation with respect to extrusion ratio; (a) As-Cast (b) 9:1 (c) $16: 1$ (d) $25: 1$ 
treatment where the discontinuous rod-type $\alpha$ precipitates dominantly nucleates and grow around grain boundaries which are the main diffusion paths at the lower aging temperature while volume diffusion plays an important role inside the $\alpha$-grain for the continuous particletype $\beta$ precipitates at the higher aging temperature. It is worth mentioning that the discontinuous rod-type and the continuous particletype $\beta$ precipitates are favored simultaneously in the microstructure forged with extruded bar with the extrusion ratio over 16:1 as shown in Figs. 10(b) and 10(c) while the continuous particle-type $\beta$ precipitates are dominantly produced with the extrusion ratio of 9:1 as shown in Fig. 10(a), which are identified to $\beta-\mathrm{Mg}_{17} \mathrm{Al}_{12}$ intermetallic compounds since these chemical compositions have $\mathrm{Mg}$ of $61.83 \%$ and $\mathrm{Al}$ of $38.17 \%, \mathrm{Mg}$ of $59.73 \%$ and $\mathrm{Al}$ of $40.27 \%$ based on the energy dispersive spectrometer (EDS) analysis as shown in Fig. 11. It is interpreted that the discontinuous rod-type precipitates tend to be favored easily when the larger fraction of the grain boundaries is produced from the higher degree of extrusion ratio.

\section{Conclusions}

This paper demonstrates the effect of the extrusion ratio on the mechanical properties of the as-forged $\mathrm{Mg}$ alloy, which is able to suggest appropriate extrusion ratio when using extruded $\mathrm{Mg}$ bars in the warm forging process. Three extruded $\mathrm{Mg}$ bars with the extrusion ratio of 9:1, 16:1, and 25: 1 are prepared in the same extrusion condition, which are applied to the warm forging test and compared with each other in terms of microstructure using OM and SEM and mechanical properties in the tensile tests.

Based on close examination, following conclusions can be drawn:

(1) As the extrusion ratio increases, mechanical properties of the asextruded bars are slightly enhanced. Especially, the extrusion ratio over 16:1 has little effect on the mechanical properties of the as-extruded bars since the average grain size and amount of precipitates hardly change.

(2) When using the extruded bar with higher extrusion ratio over 16:1, the forgeability at the elevated forming temperature is noticeably improved around flange area while the mechanical properties are slightly enhanced.

(3) The fracture elongation of the as-forged Mg part is hardly affected by the degree of the extrusion ratio of the extruded bars.

(4) The discontinuous rod-type and the continuous particle-type $\beta$ precipitates are favored simultaneously in the microstructure forged with extruded bar with the extrusion ratio over 16:1 since the fraction of grain boundaries which are the main diffusion path increases as the extrusion ratio increases.

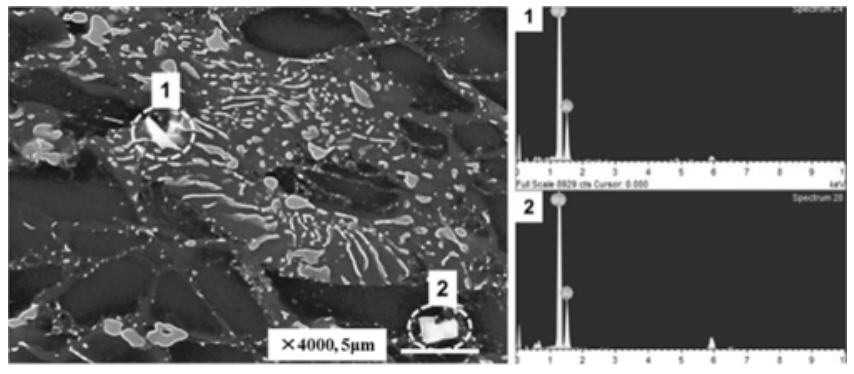

Fig. 11 EDS analysis on precipitates in forged microstructure

\section{REFERENCES}

1. Al-Samman, T. and Gottstein, G., "Room Temperature Formability of a Magnesium AZ31 Alloy: Examining the Role of Texture on the Deformation Mechanisms," Materials Science and Engineering: A, Vol. 488, No. 1, pp. 406-414, 2008.

2. Yoon, J. H. and Park, S. H., "Fogeability Test of Extruded Mg-SnAl-Zn Alloys under Warm Forming Conditions," Materials \& Design, Vol. 55, pp. 300-308, 2014.

3. Zheng, X., Dong, J., Yin, D., Liu, W., Wang, F., et al., "Forgeability and Die-Forging Forming of Direct Chill Casting Mg-Nd-Zn-Zr Magnesium Alloy," Materials Science and Engineering: A, Vol. 527, No. 16, pp. 3690-3694, 2010.

4. Lee, E.-S., Won, J.-K., Shin, T.-H., and Kim, S.-H., "Investigation of Machining Characteristics for Electrochemical Micro-Deburring of the AZ31 Lightweight Magnesium Alloy," Int. J. Precis. Eng. Manuf., Vol. 13, No. 3, pp. 339-345, 2012.

5. Rashid, R. A. R., Sun, S., Wang, G., and Dargusch, M. S., "Experimental Investigation of Laser Assisted Machining of AZ91 Magnesium Alloy," Int. J. Precis. Eng. Manuf., Vol. 14, No. 7, pp. 1263-1265, 2013.

6. Shin, K.-H., Lee, Y.-S., and Kim, H. S., "The Flow Behavior Modeling of AZ61 Magnesium Alloy at Elevated Temperatures Considering the Effects of Strain Rate and Grain Size," Int. J. Precis. Eng. Manuf., Vol. 15, No. 4, pp. 745-751, 2014.

7. Yoon, J. H., Cazacu, O., and Mishra, R. K., "Constitutive Modeling of AZ31 Sheet Alloy with Application to Axial Crushing," Materials Science and Engineering: A, Vol. 565, pp. 203-212, 2013.

8. Yoon, J. H., Lee, Y. S., and Huh, H., "Investigation of Deformation and Collapse Mechanism for Magnesium Tube in Axial Crushing Test," Journal of Mechanical Science and Technology, Vol. 27, No. 10, pp. 2917-2921, 2013.

9. Skubisz, P., Siñczak, J., and Bednarek, S., "Forgeability of Mg-Al-Zn Magnesium Alloys in Hot and Warm Closed Die Forging," Journal of Materials Processing Technology, Vol. 177, No. 1, pp. 210-213, 2006.

10. Shan, D., Xu, W., and Lu, Y., "Study on Precision Forging Technology for a Complex-Shaped Light Alloy Forging,” Journal of Materials Processing Technology, Vol. 151, No. 1, pp. 289-293, 2004.

11. Qiang, W., Zhang, Z.-M., Zhang, X., and Yu, J.-M., "Precision Forging Technologies for Magnesium Alloy Bracket and Wheel," Transactions of Nonferrous Metals Society of China, Vol. 18, pp. s205-s208, 2008.

12. Tong, L., Zheng, M., Cheng, L., Kamado, S., and Zhang, H., "Effect of Extrusion Ratio on Microstructure, Texture and Mechanical Properties of Indirectly Extruded Mg-Zn-Ca Alloy," Materials Science and Engineering: A, Vol. 569, pp. 48-53, 2013.

13. Wen, L., Ji, Z., and Li, X., "Effect of Extrusion Ratio on Microstructure and Mechanical Properties of Mg-Nd-Zn-Zr Alloys Prepared by a Solid Recycling Process," Materials Characterization, Vol. 59, No. 11, pp. 1655-1660, 2008. 
14. Chen, Y., Wang, Q., Peng, J., Zhai, C., and Ding, W., "Effects of Extrusion Ratio on the Microstructure and Mechanical Properties of AZ31 Mg Alloy,” Journal of Materials Processing Technology, Vol. 182, No. 1, pp. 281-285, 2007.

15. Uematsu, Y., Tokaji, K., Kamakura, M., Uchida, K., Shibata, H., et al., "Effect of Extrusion Conditions on Grain Refinement and Fatigue Behaviour in Magnesium Alloys," Materials Science and Engineering: A, Vol. 434, No. 1, pp. 131-140, 2006.

16. Chang, L., Wang, Y., Zhao, X., and Qi, M., "Grain Size and Texture Effect on Compression Behavior of Hot-Extruded Mg-3Al-1Zn Alloys at Room Temperature," Materials Characterization, Vol. 60, No. 9, pp. 991-994, 2009.

17. Braszczynska-Malik, K. N., "Discontinuous and Continuous Precipitation in Magnesium-Aluminium Type Alloys," Journal of Alloys and Compounds, Vol. 477, No. 1, pp. 870-876, 2009.

18. Vollertsen, F. and Schmidt, F., "Dry Metal Forming: Definition, Chances and Challenges,” Int. J. Precis. Eng. Manuf.-Green Tech., Vol. 1, No. 1, pp. 59-62, 2014.

19. Fatemi-Varzaneh, S., Zarei-Hanzaki, A., and Beladi, H., "Dynamic Recrystallization in AZ31 Magnesium Alloy," Materials Science and Engineering: A, Vol. 456, No. 1, pp. 52-57, 2007.

20. Del Valle, J. and Ruano, O. A., "Influence of Texture on Dynamic Recrystallization and Deformation Mechanisms in Rolled or Ecaped AZ31 Magnesium Alloy," Materials Science and Engineering: A, Vol. 487, No. 1, pp. 473-480, 2008.

21. Wang, P., Lin, H., Lin, K., Lin, M., Yeh, M., et al., "Effects of T5 Treatment on the Microstructure and Mechanical Properties of Mg8AL-2Li Alloy," Materials Transactions, Vol. 52, No. 7, pp. 13631368, 2011. 